\title{
APLICAÇÃO DE CONDIMENTOS NA REVELAÇÃO DE IMPRESSÕES DIGITAIS LATENTES: UM EXPERIMENTO NO ENSINO DE QUÍMICA
}

\author{
Caroline Nicolodia, Bruno Nunes da Rosa ${ }^{a}$, Caroline Carapina da Silva ${ }^{a}$, Lucas Moraes Berneira ${ }^{a}$, Bruna S. Pacheco ${ }^{a}$, Tais \\ Polettia $^{\text {, Dalila Venzke }}$, Kristiane C. Mariotti ${ }^{\mathrm{b}, \mathrm{c}}$ e Claudio M. P. Pereira ${ }^{\mathrm{a}, \mathrm{c}, *,(1)}$ \\ aDepartamento de Química Forense, Centro de Ciências Químicas Farmacêuticas e dos Alimentos, Universidade Federal de Pelotas, \\ 96010-900 Pelotas - RS, Brasil \\ ${ }^{\text {b} G r u p o ~ d e ~ I d e n t i f i c a c ̧ a ̃ o, ~ P o l i ́ c i a ~ F e d e r a l, ~ S u p e r i n t e n d e ̂ n c i a ~ R e g i o n a l ~ n o ~ R i o ~ G r a n d e ~ d o ~ S u l, ~} 90610093$ Porto Alegre - RS, Brasil \\ 'Instituto Nacional de Ciência e Tecnologia Forense (INCT Forense), Porto Alegre - RS, Brasil
}

Recebido em 26/04/2019; aceito em 24/07/2019; publicado na web em 30/08/2019

\begin{abstract}
APPLICATION OF SPICES ON THE DEVELOPMENT OF LATENT FINGERMARKS: AN EXPERIMENT IN CHEMISTRY TEACHING. The development of fingermarks is an important step in criminal cases. Latent fingermarks require applications of reagents to be developed before they can be visualized. Different techniques to enhance fingermarks' visualization have been employed and the powder dusting is the most common among them. The use of food spices as latent fingermarks developers could be an alternative method of experiment in chemistry teaching, considering that they are low cost and accessible. In this work, an experimental methodology was developed and can be applied in undergraduate chemistry teaching for the extraction of components from food spices, their chromatographic analysis and application on the development of latent fingermarks.
\end{abstract}

Keywords: food spices; fingerprints; forensic science; powder dusting.

\section{INTRODUÇÃO}

Os produtos naturais são utilizados há muito tempo pelo homem. Há relatos históricos do seu emprego por civilizações Orientais e Ocidentais no tratamento de doenças, controle de pragas e como venenos para fins de defesa e caça. ${ }^{1}$ Em especial, o processo de colonização portuguesa no Brasil ocorreu como resultado da busca por novas rotas do comércio de produtos naturais chamados de especiarias. As especiarias mais valorizadas na época eram a pimenta do reino, noz moscada, cravo e canela. ${ }^{2}$

Nesse contexto, a pintura dos corpos e cabelos dos povos indígenas chamou a atenção dos colonizadores portugueses. ${ }^{3}$ A tintura vermelha que os indígenas utilizavam era feita com frutos do urucum, cujo principal corante é o norcarotenóide bixina. Os indígenas também usavam a seiva do fruto jenipapo para fazer tatuagens de cores pretas, sendo o iridoide genipina a substância responsável pela coloração. Além disso, também há relatos do uso da andirobina como corante natural. ${ }^{1,3}$ A partir do Pau-Brasil os indígenas obtinham um corante vermelho usado para escrever e tingir fibras de algodão. ${ }^{1-3}$ Nessa época, haviam somente os corantes naturais e estes eram de grande interesse por parte dos colonizadores, sendo que o Pau-Brasil foi um dos produtos explorados pelos colonizadores até quase sua extinção. $^{1}$

Alguns compostos presentes nos produtos naturais como carotenóides, iridoides, purinas, pterinas, flavinas, fenazinas, fenoxazinas, betalaínas, antocianinas, clorofila, benzoquinonas, naftoquinonas, antraquinonas, melanina e flavonoides são responsáveis pela sua pigmentação. ${ }^{4,5}$ Os corantes naturais são muito utilizados em alimentos, como indicadores de $\mathrm{pH}$, em cosméticos e na produção de tintas. ${ }^{6-8}$ Alguns condimentos também apresentam substâncias corantes em sua composição, como é o caso do condimento cúrcuma obtido da espécie Curcuma longa L. que tem como principal corante a curcumina. ${ }^{9} \mathrm{~A}$ cúrcuma é principalmente utilizada como condimento, entretanto possui outras aplicações na área de cosméticos, têxtil e alimentícia.

*e-mail: lahbbioufpel@gmail.com
Também possui importância medicinal sendo utilizada na farmacopéia asiática como estomáquica, estimulante, carminativa, expectorante, anti-helmíntica e antiinflamatória. ${ }^{2,10}$ Além disso, há relatos de atividade antioxidante e antimicrobiana do óleo essencial de cúrcuma. ${ }^{2,11}$ Recentemente, foi descrita a aplicação da espécie $C$. longa como revelador de impressão digital. ${ }^{9}$ A presença do componente majoritário curcumina, principal responsável pela sua pigmentação torna a cúrcuma um potencial revelador. ${ }^{9}$

Contextualizando, há evidências de que os antigos hominídeos deixavam suas impressões digitais gravadas em cerâmicas e tijolos, sendo de forma decorativa ou não intencional. Alguns arqueólogos registraram que essas marcas serviam como assinatura, ou seja, como meio de identificação de quem confeccionou a obra. ${ }^{12}$ Nesse sentido, a identificação humana sempre esteve presente, principalmente para a classificação criminal. Os primeiros métodos utilizados para identificação de um indivíduo eram baseados em medidas do corpo, porém, devido às limitações e a dificuldade em alguns casos, as impressões passaram a ser essenciais como meio de identificação. ${ }^{13}$

A revelação de impressões digitais é de fundamental importância nas investigações forenses. O padrão das linhas de fricção presente na pele das mãos e dos pés, que formam impressões digitais, palmares e plantares, é único em cada indivíduo e pode ser considerado uma evidência física presente em uma cena de crime. ${ }^{9}, 14$ A papiloscopia é uma área da criminalística que trata do estudo das impressões digitais, palmares e plantares. ${ }^{13}$ Para fins de classificação, a papiloscopia está subdividida em três áreas, datiloscopia (impressões digitais), quiroscopia (impressões palmares) e podoscopia (impressões plantares). ${ }^{13}$ As impressões digitais também podem ser classificadas em latentes, patentes ou plásticas. ${ }^{4}$ Impressões digitais que não são visíveis a olho nu são denominadas latentes e necessitam ser reveladas com reagentes específicos para que possam ser visualizadas. ${ }^{14}$

A maioria dos métodos de revelação de impressão digital é baseada na interação entre as substâncias presente nela e reagentes químicos e/ou físicos. O tipo do método escolhido irá depender, dentre outros fatores, da condição e do tipo de substrato no qual a impressão está depositada. ${ }^{15} \mathrm{~A}$ principal fonte que compõe as marcas papilares 
é o suor écrino, pois não existem glândulas sebáceas nas cristas de fricção. No entanto, uma impressão digital pode ser classificada como uma mistura de substâncias originadas a partir de diferentes fontes: (1) epiderme; (2) glândulas secretórias da derme e (3) contaminantes extrínsecos. Assim, pode-se encontrar nela substâncias como: aminoácidos, proteínas, ureia, ácido lático, açúcares,${ }^{16}$ compostos gordurosos e óleos (provenientes da contaminação por meio do toque em outras partes do corpo como, testa, cabelo, pescoço e outras áreas nas quais as glândulas sebáceas liberam componentes oleosos em grandes concentrações). ${ }^{12,17,18}$

Diversos reagentes são utilizados para revelação de impressões digitais latentes, tais como ninidrina, iodo e nitrato de prata, além da utilização de pós, sendo cada um deles efetivo para diferentes superfícies. ${ }^{9}$ Novas técnicas e reagentes têm sido desenvolvidos para detectar impressões papilares latentes, porém o método mais utilizado atualmente entre os peritos papiloscopistas é o empoamento. ${ }^{19,20}$ Essa técnica vem sendo usada desde o final do século XIX por pesquisadores que estudaram padrões de variadas composições de pós, sendo Edward Richard Henry quem classificou a fórmula para revelar impressões digitais, sugerindo um pó à base de mercúrio e grafite. ${ }^{21}$

Nosso laboratório tem apresentado alguns estudos relacionados à química forense, como a análises de medicamentos e anabolizantes aprendidos pela Policia Federal e, recentemente, apresentamos alguns estudos de diferentes corantes sintéticos com aplicação odontológica na identificação de restauros. ${ }^{22-24}$ No sentido de continuar os nossos estudos em ciências forenses, este trabalho propôs a utilização dos condimentos Curcuma longa (cúrcuma), Murraya koenigii L. (curry), Cinnamomum verum J. (canela), Laurus nobilis L. (louro) e Capsicum annuum L. (páprica) como reveladores de impressões digitais, bem como a análise cromatográfica dos mesmos objetivando a aplicação no ensino de Química em Cursos técnicos e de Graduação. Conteúdos na área de cromatografia e química orgânica estão inseridos nestes experimentos a fim de valorizar o conhecimento dos estudantes.

\section{PROCEDIMENTO EXPERIMENTAL}

Este experimento pode ser aplicado aos cursos de Graduação e Técnicos em Química, Farmácia e Toxicologia e pode ser dividido em cinco aulas, sendo uma aula destinada à obtenção dos extratos dos temperos e análise por Cromatografia em Camada Delgada (CCD), duas aulas destinadas para análises por Cromatografia Gasosa Acoplada à Espectrometria de Massas (CG-EM) e interpretação de dados e duas aulas destinadas para os testes de revelação de impressões digitais.

\section{Materiais e métodos}

Os solventes utilizados para extração dos condimentos (hexano, acetato de etila e acetona) foram adquiridos da Dinâmica ${ }^{\circledR}$ e o sulfato de sódio anidro foi obtido da Synth ${ }^{\circledR}$. Para a obtenção de perfil cromatográfico dos extratos por CCD foi utilizada uma placa de alumínio recoberta com sílica gel $60(5-40 \mu \mathrm{m})$ da Merck, com 0,25 mm de espessura. Foram utilizados padrões de trans-cinamaldeído obtida da Acros Organics ${ }^{\circledR}$ e cumarina e eugenol obtidos da Sigma Aldrich ${ }^{\circledR}$. Os compostos separados nas placas foram revelados sob visualização em lâmpada ultravioleta (UV) a $254 \mathrm{~nm}$ e com o reagente anisaldeídosulfúrico seguido de aquecimento a $110^{\circ} \mathrm{C}$.

Para a realização dos testes de revelação de impressão digital utilizou-se os pincéis 132LBW e CFB100, adquiridos da Sirchie $^{\circledR}$. A captura das imagens foi realizada com uma câmera semi-profissional Canon ${ }^{\circledR}$ EOS Rebel T6 com distância de $9 \mathrm{~cm}$ e foco 5.6.

\section{Seleção e obtenção das especiarias}

Os condimentos foram selecionados por apresentarem corantes naturais, podendo, portanto, apresentar contraste suficiente para serem usados como reveladores de impressões digitais. Todos os condimentos foram adquiridos do comércio de especiarias da cidade de Pelotas. Com exceção da páprica, que é de origem peruana, os demais condimentos são de origem asiática.

\section{Extração dos corantes}

A extração foi realizada a partir da adaptação de um método previamente reportado na literatura. ${ }^{25}$ Inicialmente, $10 \mathrm{~g}$ de cada tempero foram pesados e pré-extraídos utilizando acetona $(5 \mathrm{~mL})$ e hexano $(15 \mathrm{~mL})$ em mesa agitadora por 30 minutos. Em seguida foi feita uma filtração e a mistura formada foi vertida para um funil de separação. Adicionou-se acetato de etila $(20 \mathrm{~mL})$ e as fases foram separadas. A fase orgânica foi lavada duas vezes com água destilada (utilizando $15 \mathrm{~mL}$ em cada etapa) e foi seca com sulfato de sódio anidro $(0,5 \mathrm{~g})$, filtrada e evaporada utilizando rota-evaporador, obtendo-se as seguintes quantidades de extrato: $0,06 \mathrm{~g}$ do extrato de C. verum, 0,20 g de C. longa, $0,11 \mathrm{~g}$ de $L$. nobilis, $0,38 \mathrm{~g}$ de $C$. annuum e $0,22 \mathrm{~g}$ de $M$. koenigii.

\section{Método de análise dos extratos obtidos}

Os extratos obtidos foram analisados por Cromatografia em Camada Delgada (CCD) utilizando como eluente uma solução Hexano e Acetato de etila 9:1 e placa de sílica gel. A revelação dos componentes do extrato foi feita utilizando luz UV $(254 \mathrm{~nm})$ e por aplicação de anisaldeído-sulfúrico e aquecimento. Posteriormente os extratos também foram analisados utilizando CG-EM da marca Shimadzu QP 2010 equipado com injetor automático e coluna capilar RTX-5 MS (30 $\mathrm{m} \times 0,25 \mathrm{~mm} \times 0,25 \mu \mathrm{m})$. Foi utilizada a seguinte programação de temperatura da coluna: $40{ }^{\circ} \mathrm{C} \mathrm{min}{ }^{-1}$, aquecendo $10^{\circ} \mathrm{C} \mathrm{min}{ }^{-1}$ até $280^{\circ} \mathrm{C}$ com isoterma nesta temperatura por $10 \mathrm{~min}$. A temperatura do injetor foi de $280^{\circ} \mathrm{C}$, da fonte de íons $200{ }^{\circ} \mathrm{C}$ e da interface $300{ }^{\circ} \mathrm{C}$. O tempo de corrida foi de 35 minutos. Os fragmentos foram detectados na faixa de razão massa carga $(\mathrm{m} / \mathrm{z})$ de $35-700$. O hélio foi usado como gás de arraste com fluxo de $1,23 \mathrm{~mL} \mathrm{~min} \mathrm{~m}^{-1} \mathrm{e}$ uma razão de split de 1:50. A identificação dos compostos foi feita utilizando o padrão de fragmentação e comparação com a biblioteca (NIST-08) e com a literatura. ${ }^{26}$

\section{Revelação das impressões digitais}

Para a deposição das impressões digitais foram utilizadas superfícies de vidro e de plástico. Foram analisadas impressões digitais latentes naturais e sebáceas para comparação da adesão dos pós dos condimentos. Para deposição das impressões digitais naturais, o doador lavou as mãos com sabão neutro e seguiu suas atividades normalmente por trinta minutos para então depositá-las. Para deposição das impressões sebáceas o doador friccionou os dedos em locais oleosos, como testa e nariz e então realizou a deposição. Após essas coletas, aguardou-se $24 \mathrm{~h}$ para realizar a revelação das impressões digitais pelo método do empoamento, utilizando-se pincéis específicos e os condimentos selecionados. Depois foi feita a captura das imagens das impressões digitais reveladas.

\section{RESULTADOS E DISCUSSÃO}

A Figura 1 traz um diagrama esquemático, sintetizando as etapas utilizadas para extração dos componentes presentes nos condimentos, para análise desses compostos e sua aplicação como reveladores de impressões digitais latentes.

Após a etapa de extração, foi realizada uma análise cromatográfica preliminar por CCD. A cromatografia é um método físico-químico 


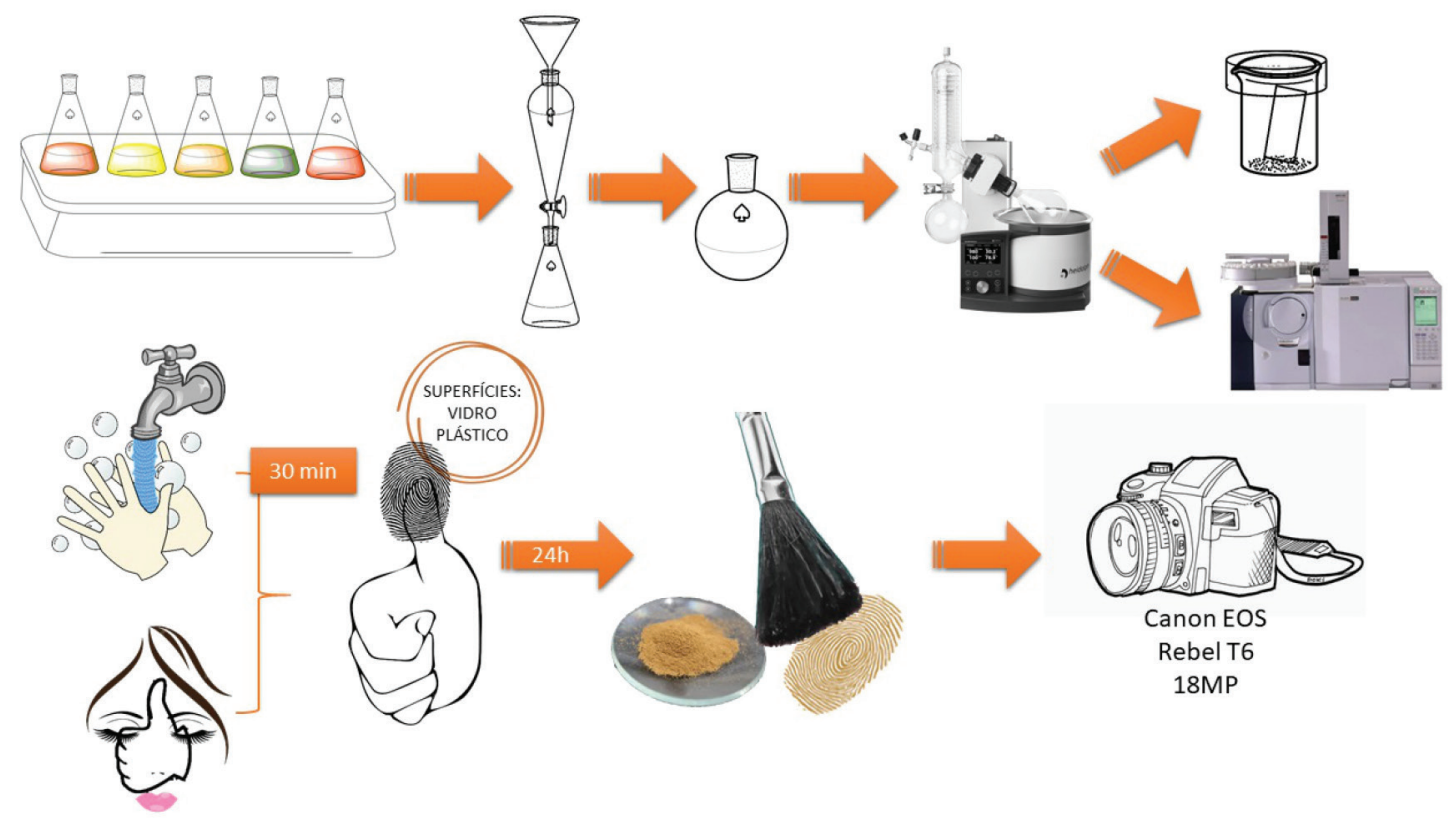

Figura 1. Diagrama esquemático da obtenção dos extratos dos condimentos e utilização como reveladores de impressão digital

muito utilizado na separação dos componentes de uma mistura realizada através da distribuição destes componentes entre duas fases: a fase estacionária e a fase móvel. Quando ocorre a passagem da fase móvel pela fase estacionária, cada componente tem uma interação diferente com a fase estacionária, o que resulta em migrações diferenciais. ${ }^{27}$ A cromatografia pode ser usada para identificar compostos quando se usa padrões para comparação, para separação de componentes de misturas e também para purificação. ${ }^{28}$ Existem várias modalidades de cromatografia, neste trabalho os extratos dos condimentos obtidos foram analisados por CCD e CG-EM. A CCD é um tipo de cromatografia cujo processo de separação é por adsorção. A separação ocorre por migração diferencial dos componentes sobre uma camada delgada de adsorvente retido sobre uma superfície plana e uma fase móvel. A fase móvel também chamado de eluente pode ser composta por um único solvente ou uma mistura de solventes. A sílica e a alumina são os adsorventes mais utilizados na cromatografia de adsorção. ${ }^{27}$ É importante salientar que a cromatografia de extratos de condimentos naturais permite uma abordagem didática e contextualizada no ensino de Química de Graduação.

As Figuras 2a e 2b mostram os cromatogramas dos extratos de condimentos obtidos por CCD e revelação com luz UV (254 nm) e anisaldeído-sulfúrico seguido de aquecimento. É possível observar a diferença de afinidade dos componentes dos extratos pela fase estacionária. Os componentes que estão mais próximos do ponto de aplicação interagem mais com a fase estacionária, sendo compostos mais polares, enquanto que os que migram mais têm menos interação com esta fase e são mais apolares. $\mathrm{O}$ fator de retenção $\left(\mathrm{R}_{f}\right)$ é um parâmetro muito importante em CCD e pode ser obtido pela razão entre a distância percorrida pela substância em questão e a distância percorrida pela fase móvel. ${ }^{27,28} \mathrm{~A}$ fim de comparação com os extratos dos produtos naturais, também foram aplicados na placa (2a) reagentes comerciais que foram usados como padrões, o que viabilizou um auxilio importante na identificação de alguns componentes. Os valores de $\mathrm{R}_{f}$ 's de todos os componentes presentes nos extratos e também dos reagentes (padrões) utilizados como cinamaldeído, eugenol e cumarina são mostrados nas Figuras $2 \mathrm{a}$ e $2 \mathrm{~b}$.

Com base nisso, pela análise comparativa preliminar dos dois cromatogramas foi possível visualizar a presença de cinco componentes com diferentes valores de $\mathrm{R}_{f}$ 's no extrato de $C$. verum, oito compostos no extrato de C. longa, cinco compostos no extrato de $M$. koenigii, três compostos no extrato de L. nobilis e quatro compostos no extrato de C. annuum. Pela análise da CCD obtida por revelação com luz UV pode-se observar que um dos componentes do extrato de $C$. verum mostrou ter o mesmo valor de $\mathrm{R}_{f}(0,25)$ da cumarina utilizada como padrão. Além disso, outro componente nesse extrato mostrou a mesma coloração ao ser revelada com anisaldeído sulfúrico e o mesmo valor de $\mathrm{R}_{f}(0,50)$ que do padrão de cinamaldeido utilizado (Figuras $2 \mathrm{~b}$ e $2 \mathrm{c}$ ).

Assim, com os resultados obtidos, pode-se observar que com esse experimento bastante simples permite a abordagem de temas importantes no ensino de química como o princípio da separação cromatográfica de misturas, questões de polaridade referentes à fase móvel e à estacionária, interpretação dos resultados analíticos, conceitos de testes preliminares e testes confirmatórios, bem como as aplicações práticas da CCD.

A composição dos extratos de temperos também foi analisada por CG-EM. Além de demonstrar uma nova técnica, permite abordar conceitos de identificação de compostos, migração diferencial, conceitos de polaridade aliados à volatilidade, avaliação e interpretação de espectro de massas, dentre outros. Tem-se essa técnica como uma das mais difundidas dentro das ciências forenses, assim sua abordagem prática e teórico-prática colabora com o ciclo de aprendizagem do aluno. Nesse sentido, foi feita uma discussão dos cromatogramas obtidos por CG-EM, abordando o perfil dos compostos capazes de serem analisados por essa técnica e, verificando, por exemplo, o número de componentes do extrato de $C$. verum (canela) que, como visto na Figura 3, é indicado pelo número de picos. No cromatograma representativo foram identificados cinco componentes e cada um deles apresenta um espectro de massas com padrão de fragmentação característico.

Ao comparar a CCD (Figura 2) e o cromatograma obtido do extrato de $C$. verum (Figura 3) é possível observar algumas relações entre os $\mathrm{R}_{f}$ 's encontrados para os constituintes no extrato e os tempos de retenção observados na análise cromatográfica. Por exemplo, comparando os constituintes cinamaldeído, eugenol e cumarina observa-se que a cumarina mostrou maior interação pela fase estacionária na CCD (Figura 2), ficando mais retida, enquanto cinamaldeido e eugenol mostraram uma menor interação, sendo que ambos mostraram valores de $\mathrm{R}_{f}$ 's bem próximos. Essa mesma tendência foi observada 

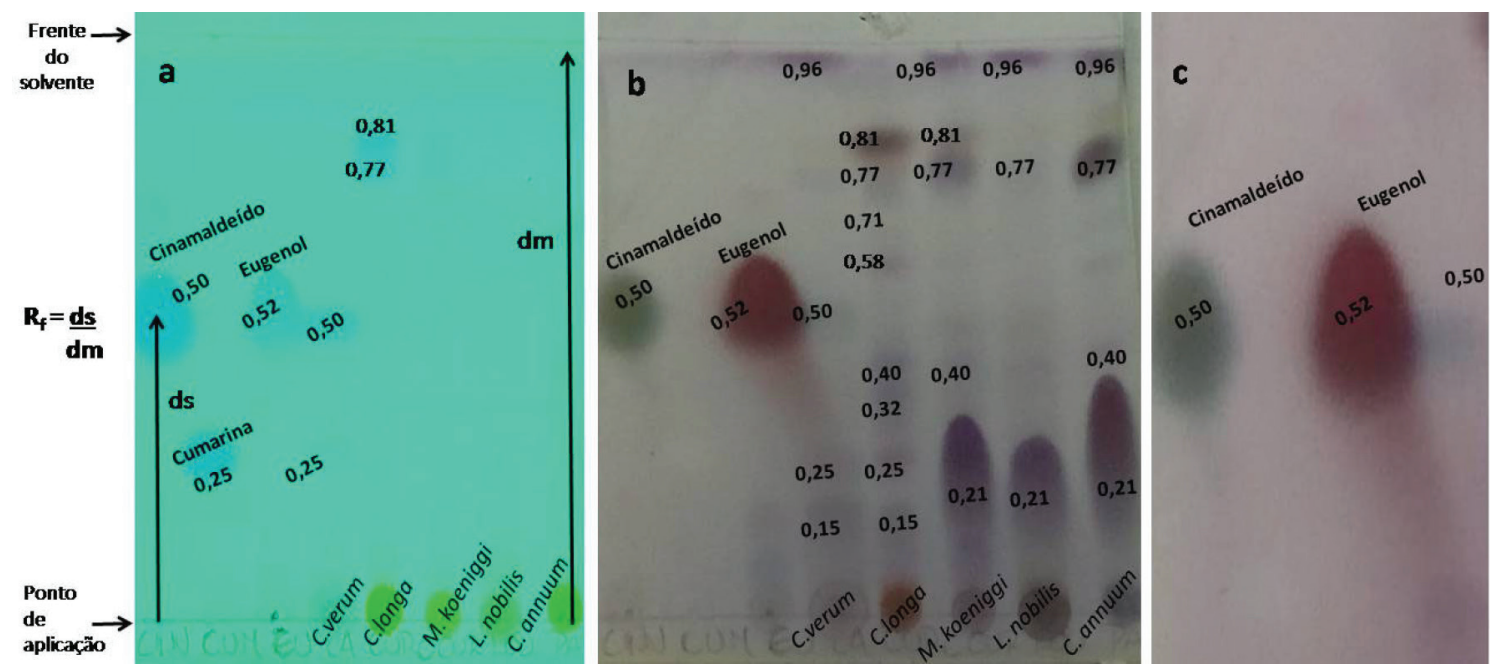

Figura 2. a) Revelação da CCD utilizando luz UV a 254nm. b) Revelação da CCD utilizando como revelador anisaldeído-sulfúrico seguido de aquecimento c) Ampliação da CCD revelada com anisaldeído-sulfúrico (b)

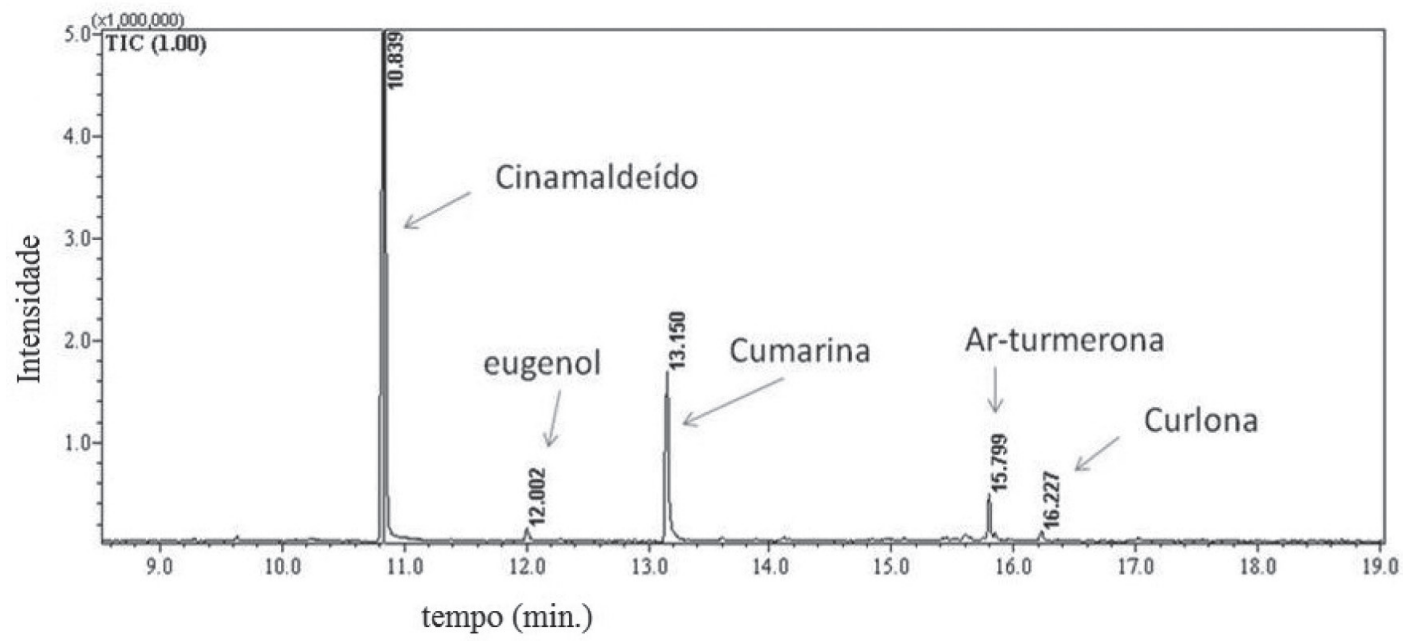

Figura 3. Cromatograma obtido pela análise em CG-EM do extrato de C. verum (canela)

no cromatograma (Figura 3 ) de $C$. verum, no qual a cumarina mostrou maior afinidade pela fase estacionária apresentando maior tempo de retenção $(13,150 \mathrm{~min})$ em relação ao cinamaldeído $(10,839 \mathrm{~min})$ e eugenol (12,002 $\mathrm{min})$.

Pode-se observar também que a eluição dos componentes de C. verum seguiu a ordem de ponto de ebulição, em que os compostos mais voláteis como cinamaldeido e eugenol eluíram mais rapidamente da coluna cromatográfica apresentando menores valores de tempo de retenção ao passo que componentes com maiores pontos de ebulição como ar-tumerona e curlona eluíram menos rapidamente, apresentando maiores valores de tempo de retenção.

Para fins didáticos, foi feita uma discussão de como foi realizada a análise do espectro de massas do pico com tempo de retenção 10,839 min (Figuras 3 e 4). A biblioteca NIST-08 sugeriu que o pico se tratava do composto cinamaldeído. Para confirmar a estrutura do composto foi feita uma análise da fragmentação do composto e comparação com a literatura. ${ }^{26}$

Pela análise do espectro de massas (Figura 4) identificou-se o íon molecular com $\mathrm{m} / \mathrm{z}$ de 132 . O íon molecular é o pico de maior $\mathrm{m} / \mathrm{z}$ que, quando detectado, indica a massa molecular do composto. Também foi identificado o pico-base, que é o pico de maior intensidade relativa, sendo nesse caso o $\mathrm{m} / \mathrm{z}$ 131. A seguir foi feita a análise do padrão de fragmentação do composto. Pela subtração do pico de $\mathrm{m} / \mathrm{z}, 132$ do pico de $\mathrm{m} / \mathrm{z}, 103$ tem-se o fragmento 29, que corresponde ao fragmento $\mathrm{HCO}^{+}$. Já da subtração do fragmento $\mathrm{m} / z, 103$ pelo fragmento $m / z 77$ tem-se o valor de $m / z 26$, que se trata do fragmento $\mathrm{C}_{2} \mathrm{H}_{2}$. O fragmento de $\mathrm{m} / z 77$ é um fragmento de anel benzênico e pela adição dos fragmentos $\mathrm{C}_{2} \mathrm{H}_{2}$ e $\mathrm{HCO}^{+}$ao anel benzênico é possível chegar à estrutura do composto cinamaldeído, confirmando o composto indicado pela biblioteca.

A identificação dos demais constituintes do cromatograma extrato de C. verum (Material Suplementar) também foi feita com base na sua fragmentação, sendo identificados no extrato: cinamaldeído, eugenol, cumarina, ar-turmerona e curlona, sendo o cinamaldeído o composto majoritário, como mostra a Tabela 1. A porcentagem dos componentes do extrato mostrados na Tabela 1 foi feita com base na integração dos picos obtidos no cromatograma (Figura 3).

A presença do cinamaldeído como componente majoritário na canela também já foi descrita previamente na literatura. ${ }^{29}$ Outros autores também reportaram a presença de compostos como cumarina, ${ }^{30}$ eugenol, ${ }^{31}$ ar-tumerona ${ }^{32}$ e curlona ${ }^{31}$ na canela.

O mesmo procedimento de identificação dos componentes do extrato de canela foi utilizado para a identificação dos componentes do extrato de C. longa. Nesse extrato (Material Suplementar) foi possível realizar a identificação dos componentes ar-tumerona, tumerona e curlona, que também foram reportados previamente por Naz e colaboradores. ${ }^{33}$ No extrato de $M$. koenigii foram observados também os componentes encontrados na cúrcuma (ar-tumerona, tumerona e 
966

Nicolodi et al.

Quim. Nova

a)

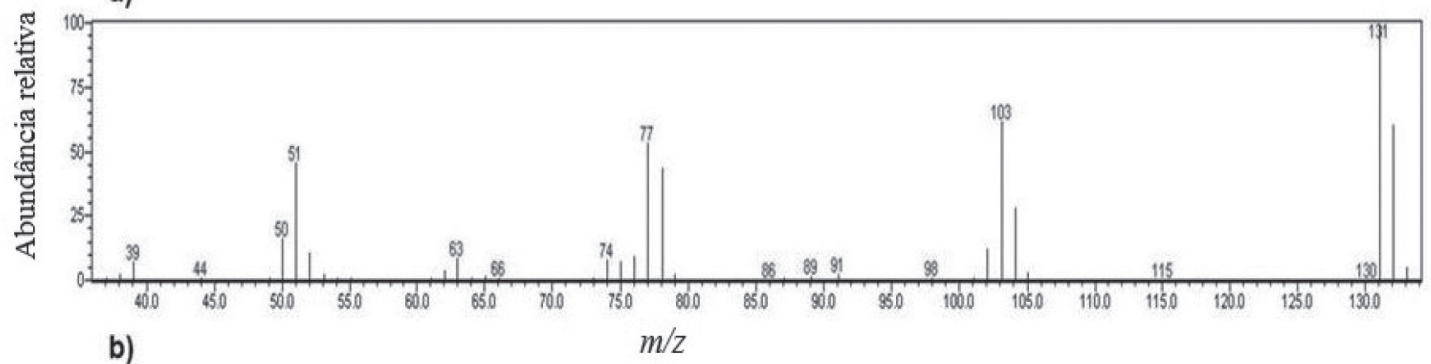

b)

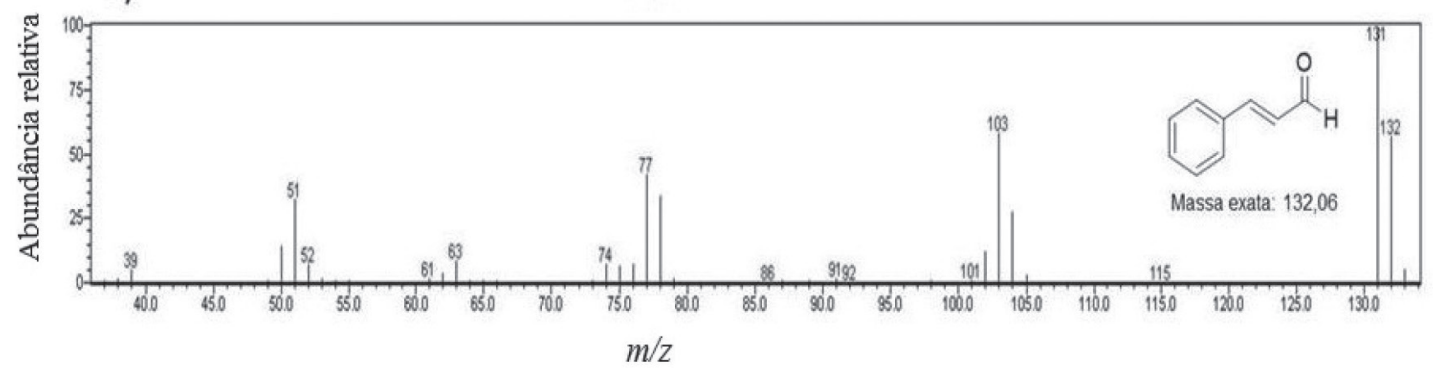

Figura 4. a) Espectro de massa do pico correspondente ao cinemaldeído b) Padrão de fragmentação fornecido pela biblioteca NIST-08

Tabela 1. Componentes identificados nos extratos dos condimentos

Componentes

ar-tumerona

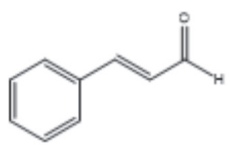

86,52

Cinamaldeído

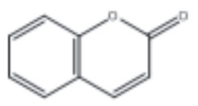

Cumarina

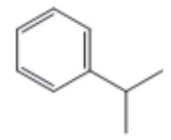

Cumeno<smiles>C=C1C=CC(C(C)CC(=O)C=C(C)C)CC1</smiles>

Curlona

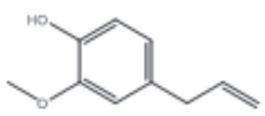

Eugenol

P

nd

0,67

0,43
38,75

nd

nd

nd

nd

nd

23,05

21,49

11,30

17,64

nd

16,13

20,62

nd

nd

nd

7,62

nd

nd

15,20

nd

25,14

Tumerona

* nd = Não identificado. 
curlona), o que já era esperado uma vez que este condimento pode apresentar cúrcuma em seu preparo, além disso, também foi identificado o eugenol no extrato (Tabela 1).

No extrato de L. nobilis foram identificados os componentes majoritários ar-tumerona, cumeno, eugenol, curlona e, em menor quantidade, o constituinte cinamaldeído. $\mathrm{O}$ extrato de $C$. annuиm apresentou como componentes majoritários ar-tumerona e tumerona, além da curlona (Tabela 1).

Todos os cromatogramas e espectros de massas dos demais extratos de condimentos encontram-se disponíveis no Material Suplementar. Pela análise do espectro de massas do eugenol extraído dos condimentos (Figura 5S) observou-se a presença de um pico-base e íon molecular de $m / z 164$ que corresponde à massa da substância. Por sua vez, a perda de $\mathrm{CH}_{3}$ e posteriormente de $\mathrm{H}_{2} \mathrm{O}$ geraram fragmentos de $m / z, 149$ e $m / z, 131$, respectivamente. Por fim, a formação do íon tropílio pode ser visto no $\mathrm{m} / \mathrm{z} 91$. Por outro lado, o espectro de massas da cumarina (Figura 6S) indicou o íon molecular de $\mathrm{m} / \mathrm{z}, 146 \mathrm{e}$ o pico-base de $\mathrm{m} / z, 118$ proveniente da fragmentação do grupo $\mathrm{C}=\mathrm{O}$.

Devido a sua isomeria, a ar-turmerona (Figura $7 \mathrm{~S}$ ) e a tumerona (Figura 9S) apresentaram fragmentações similares, tendo um íon molecular de $m / z, 216$ e pico-base de $m / z$ 89. A perda de $\mathrm{CH}_{3}$ gerou o fragmento de $m / z 201$ ao passo que subsequentes fragmentações nas moléculas geraram os íons tropílio $(\mathrm{m} / \mathrm{z}, 91)$. Por sua vez, a curlona (Figura 8S) apresentou um pico-base de $\mathrm{m} / \mathrm{z} 120$ ao passo que o íon molecular não pode ser observado possivelmente devido a sua baixa estabilidade. A fragmentação de $\mathrm{C}_{8} \mathrm{H}_{13} \mathrm{O}$ gerou o fragmento de $m / z$ 120. A análise do espectro do cumeno (Figura 10S) indicou um íon molecular de $\mathrm{m} / \mathrm{z}, 120$ e um pico-base de $\mathrm{m} / \mathrm{z}, 105$ devido a retirada de um grupo $\mathrm{CH}_{3}$. Por fim, o íon tropílio pode ser visto no $\mathrm{m} / \mathrm{z}$.91. Com base nas fragmentações, picos-base e íons moleculares, todas as moléculas extraídas puderam ter sua estrutura confirmada.

Para analisar o potencial dos condimentos como reveladores de impressões digitais latentes foram selecionados diferentes doadores de impressões. A partir disso, os condimentos utilizados foram aplicados nas diferentes superfícies (vidro e plástico) e foi avaliada a eficácia de revelação de impressões digitais naturais, como a presença de detalhes da crista papilar que são os relevos presentes nas pontas dos dedos e são responsáveis pelos desenhos das impressões digitais. Nesse sentido, para avaliar a qualidade das impressões digitais reveladas, foi empregada a escala desenvolvida por Sears e colaboradores, ${ }^{34}$ conforme Tabela 2.

Fundamentando-se nisso, as Figuras 5 e 6 apresentam a revelação das impressões digitais, naturais e sebáceas, com aplicação de C. verum e L. nobilis, respectivamente. É possível observar que as
Tabela 2. Classificação para avaliação de impressões digitais reveladas

\begin{tabular}{ll}
\hline Avaliação & \multicolumn{1}{c}{ Nível de detalhes } \\
\hline 0 & Sem evidência de impressão digital \\
\hline 1 & $\begin{array}{l}\text { Revelação ruim; evidência de interação, mas sem detalhes da } \\
\text { crista papilar }\end{array}$ \\
\hline 2 & $\begin{array}{l}\text { Revelação limitada; cerca de } 1 / 3 \text { dos detalhes da crista papilar } \\
\text { estão presentes, mas provavelmente não podem ser usados para } \\
\text { fins de identificação }\end{array}$ \\
\hline 3 & $\begin{array}{l}\text { Revelação boa; entre } 1 / 3 \text { e } 2 / 3 \text { dos detalhes da crista papilar; } \\
\text { impressão digital identificável }\end{array}$ \\
\hline 4 & $\begin{array}{l}\text { Revelação muito boa; todos detalhes de crista papilar; impressão } \\
\text { digital identificável }\end{array}$ \\
\hline
\end{tabular}

especiarias são promissoras, proporcionando impressões digitais com nível de detalhamento entre 3 e 4 , conforme escala acima, com destaque para o emprego de $C$. verum, que apresentou os melhores resultados para os dois tipos de superfícies utilizados, tanto em impressões naturais quanto sebáceas reveladas após 24 h da deposição.

As Figuras 7 e 8 ilustram a aplicação da C. longa e M. koenigii, respectivamente, de modo que estes temperos apresentaram nível de detalhamento entre 2 e 3 , conforme escala empregada, apresentando uma interação maior com as impressões digitais sebáceas, gerando melhor revelação nesse tipo de impressão digital. Apesar de em alguns casos não ser possível evidenciar a impressão digital, não se descarta o emprego desses como alternativas aos métodos convencionais de aplicação de pós, principalmente para fins didáticos. Cabe ressaltar que as impressões digitais variam de pessoa para pessoa, sendo influenciadas por características do doador, como: alimentação, sexo, idade, entre outros..$^{35}$

Diferentemente dos demais pós utilizados, a páprica apresentou os resultados menos promissores e não foi possível obter imagens para impressões naturais (Figura 9). Para as impressões sebáceas houve pouca interação com as marcas, não resultando em revelações capazes de serem utilizadas para fins de identificação humana. Isso pode ser explicado devido à retenção de umidade (hidrofilia) observada para este condimento, o que ocasionou a formação de grânulos e, consequentemente, o aumento no tamanho das partículas, dificultando a adesão seletiva às cristas da impressão digital, característica responsável pela definição da revelação.

Nesse sentido, a técnica de revelação de impressões digitais latentes por pós é caracterizada por ser um método físico, porém, a composição química do material auxilia na fixação sobre a impressão

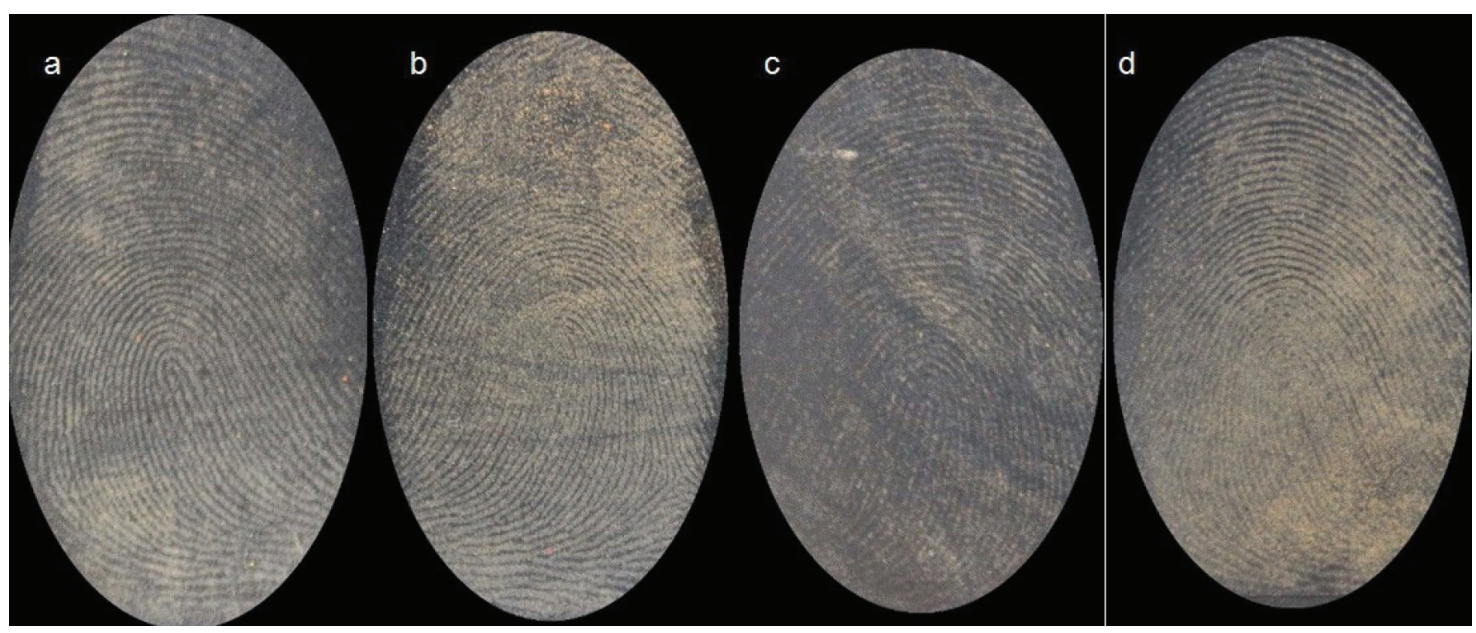

Figura 5. Impressões digitais latentes (a) natural e (b) sebácea reveladas em vidro e (c) natural e (d) sebácea revelada em plástico utilizando C. verum como revelador 


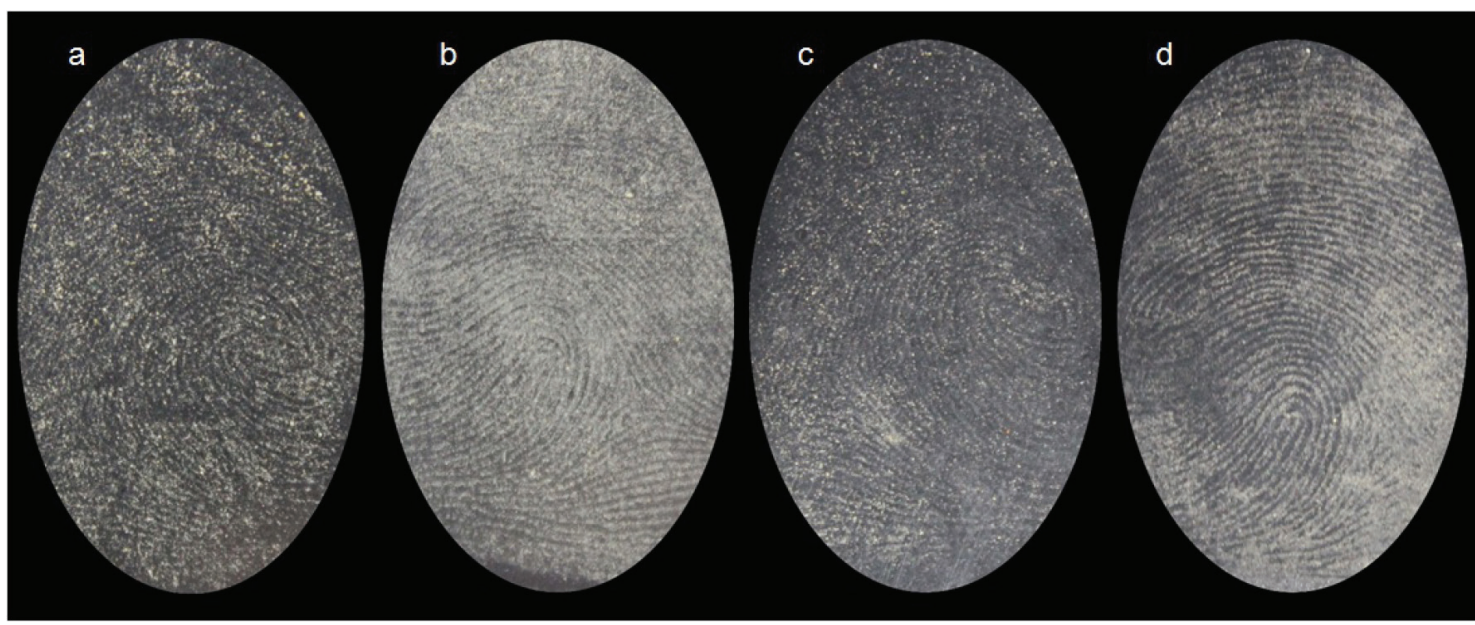

Figura 6. Impressões digitais latentes (a) natural e (b) sebácea reveladas em vidro e (c) natural e (d) sebácea revelada em plástico utilizando L. nobilis como revelador

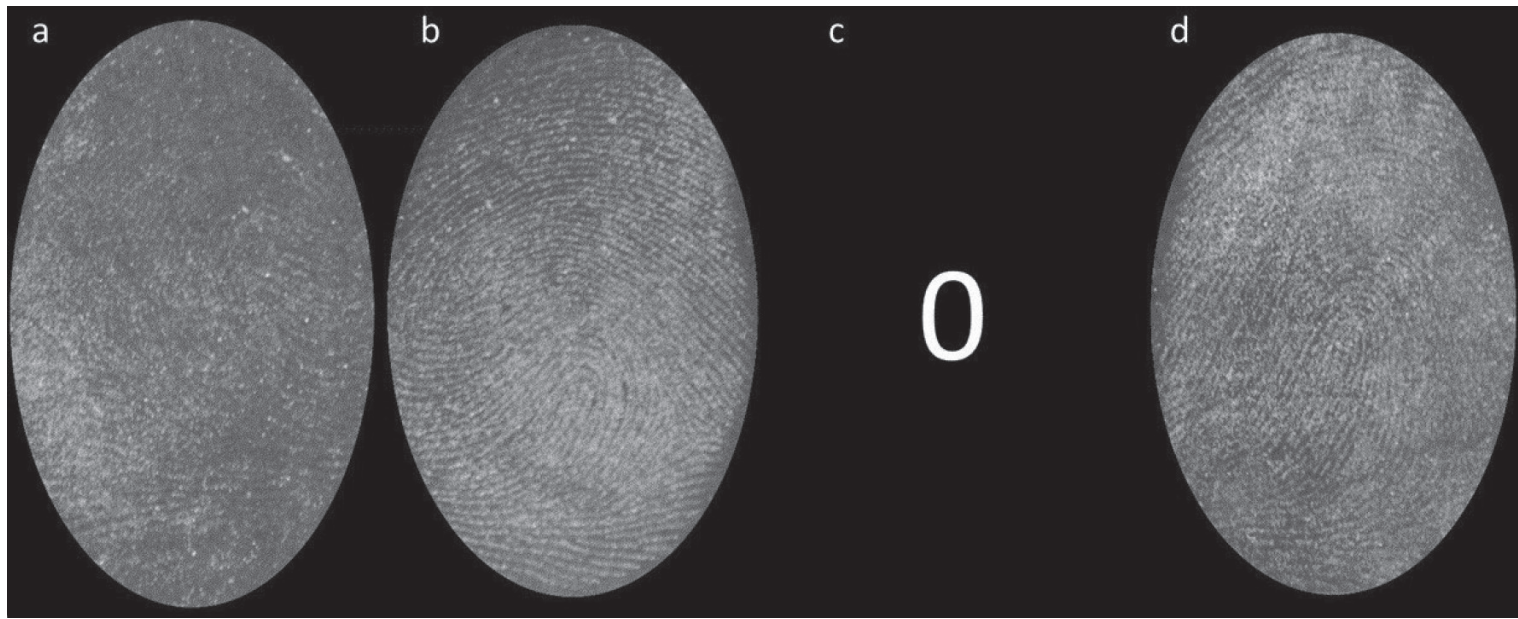

Figura 7. Impressões digitais latentes (a) natural e (b) sebácea reveladas em vidro e (c) natural e (d) sebácea revelada em plástico utilizando C. longa como revelador; 0: sem evidência de impressão digital

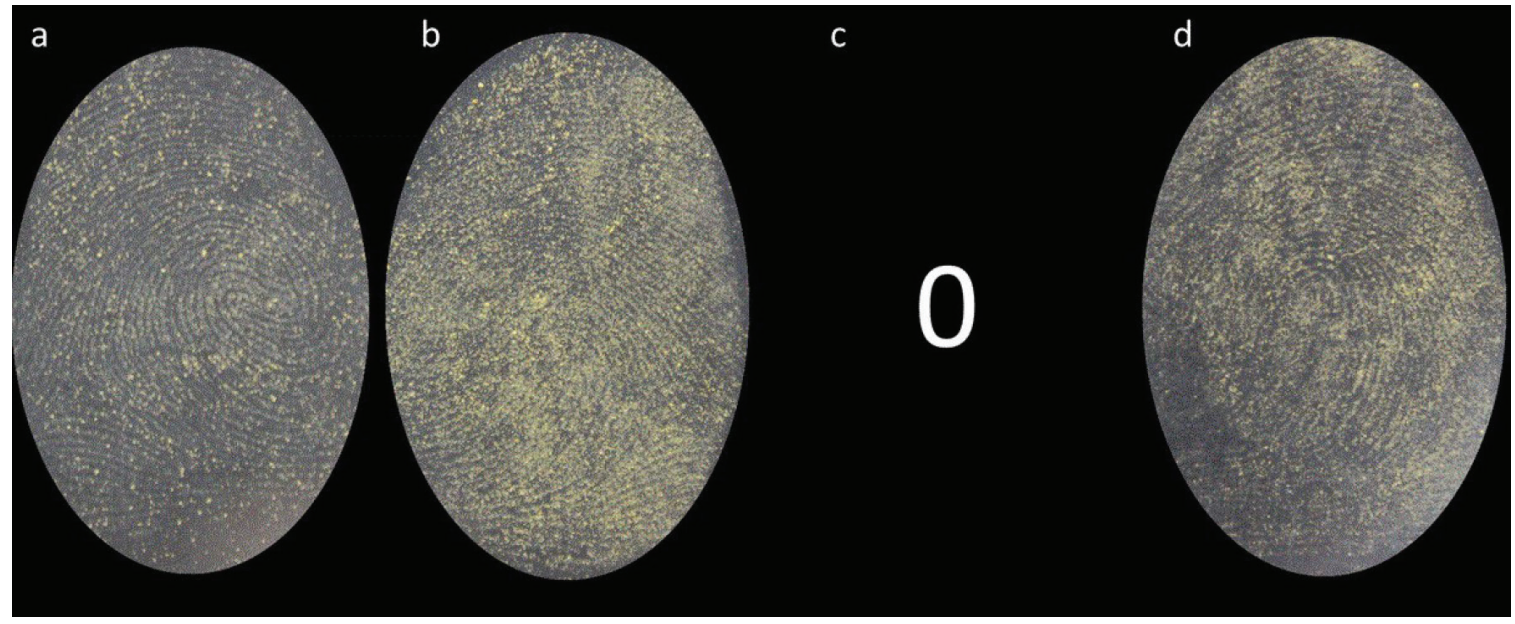

Figura 8. Impressões digitais latentes (a) natural e (b) sebácea reveladas em vidro e (c) natural e (d) sebácea revelada em plástico utilizando M. koenigii como revelador; 0 : em evidência de impressão digital)

digital. Desse modo, as partículas dos condimentos aderem ao resíduo lipofílico da impressão digital enquanto as demais partículas aderem por forças de Van der Waals, dependendo da partícula e do resíduo, desde que estejam suficientemente próximos. ${ }^{36}$

Por fim, cabe salientar que, com esse experimento, é possível trazer ao aluno noções sobre extração de produtos naturais, cromatografia, interpretação de resultados analíticos e ciências forenses, especificamente, a papiloscopia. A utilização dessas substâncias como reveladores de impressões digitais latentes para fins didáticos têm como princípio ampliar a aprendizagem, estabelecendo lúcidas conexões entre teoria e prática, contemplando entendimentos de química aplicada e favorecendo o interesse 


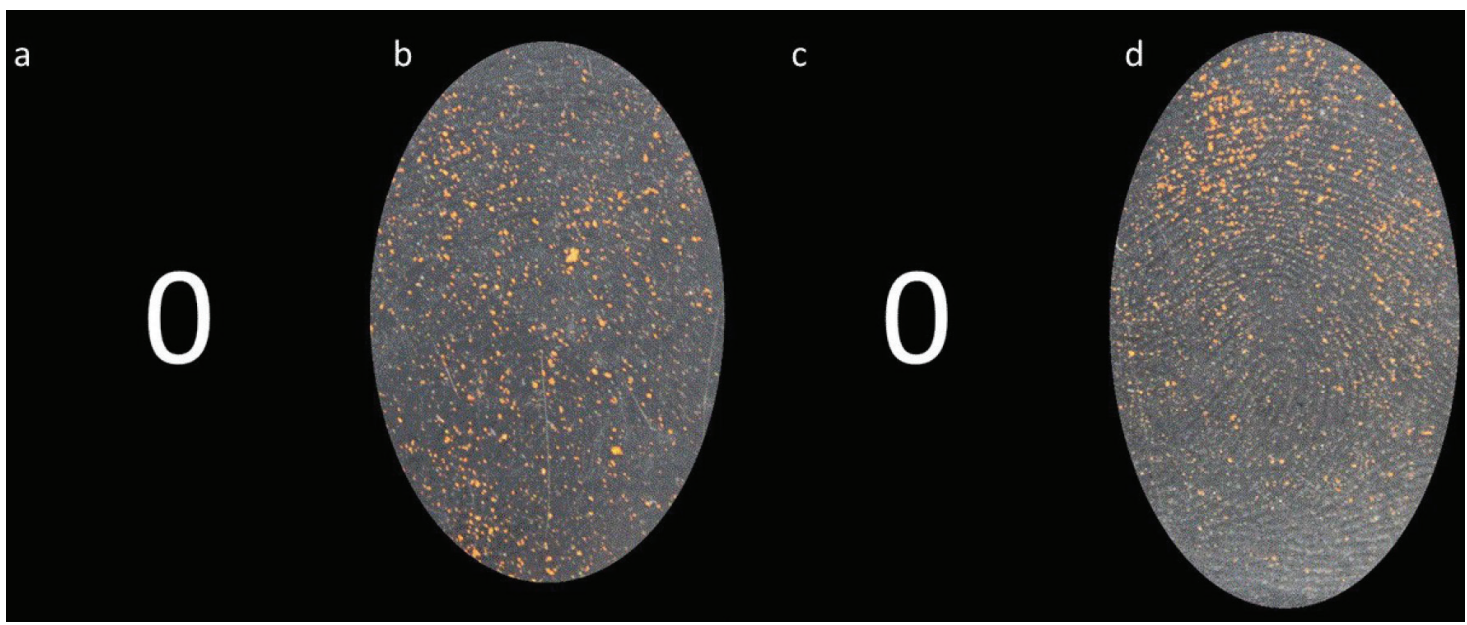

Figura 9. Impressões digitais latentes (a) natural e (b) sebácea reveladas em vidro e (c) natural e (d) sebácea revelada em plástico utilizando C. annuum como revelador; 0: sem evidência de impressão digital)

pelas aulas, visto que a química forense é uma área em ascensão. ${ }^{37}$ Além disso, esses compostos são de fácil obtenção, apresentam baixo custo quando comparados a pós preconizados para revelação de impressões digitais latentes, e apresentam baixa toxicidade, viabilizando a utilização em laboratório de forma segura para os alunos.

\section{CONCLUSÃO}

O experimento proposto no presente trabalho pode ser aplicado no ensino de Química aos cursos de Graduação e Técnicos em Química, Farmácia e Toxicologia, nos quais é possível fazer uma abordagem teórica e prática sobre extração de compostos de produtos naturais, $\mathrm{CCD}, \mathrm{CG}-\mathrm{EM}$, num contexto de química aplicada às ciências forenses, especificamente na papiloscopia, o que favorece o interesse do aluno, dada a repercussão prática do tema. É importante salientar que os condimentos selecionados mostraram ser bons reveladores de impressões digitais, tanto naturais quanto sebáceas, em superfícies de plástico e de vidro. Além disso, os extratos selecionados são de fácil acesso, baixo custo e baixa toxicidade, o que permite o seu uso em sala de aula.

\section{MATERIAL SUPLEMENTAR}

O material suplementar relacionado a este artigo encontra-se disponível em http://quimicanova.sbq.org.br, em formato PDF, com acesso livre.

\section{AGRADECIMENTOS}

Os autores agradecem ao Instituto Nacional de Ciência e Tecnologia (INCT Forense - CNPq 465450/2014-8), ao Conselho Nacional de Desenvolvimento Científico e Tecnológico (CNPq) e à CAPES (Coordenação de Aperfeiçoamento de Pessoal de Nível Superior) pelo suporte financeiro.

\section{REFERÊNCIAS}

1. Viegas, C.; Bolzani, V. S.; Barreiro, E. J.; Quim. Nova 2006, 29, 326.

2. Rodrigues, R. S.; Silva, R. R.; Quim. Nova Esc. 2010, $32,84$.

3. Almeida, M. R.; Martinez, S. T.; Pinto, A. C.; Rev. Virtual Quim. 2017, 9, 1117.

4. Delgado-Vargas, F.; Jiménez, A. R.; Paredes-López.; Crit. Rev. Food Sci. Nutr. 2000, 40, 173.
5. Bianchini, R.; Penteado, M. V. C.; Food Sci. Technol. 1998, 18, 283.

6. Suganya, K.; Preethi, P. S.; Suganya, M.; Nanthini, A. U. R.; International Journal of Pharmaceutical Sciences and Business Management 2016, 4, 7 .

7. Janiszewska-Turak, E.; Pisarska, A.; Królczyk, J. B.; Nauka Przyr. Technol. 2016, 10, 51

8. Yusuf, M.; Shabbir, M.; Mohammad, F.; Nat. Prod. Bioprospect. 2017, 7, 123.

9. Garg, R. K.; Kumari, H.; Kaur, R.; Egyptian Journal of Forensic Sciences 2011, 1, 53.

10. Pereira, C. M. P.; Pacheco, B. S.; Silva, C. C.; Curcumin and analogues: chemical and biological aspects, $1^{\text {st }}$ ed., Lambert Academic Publishing: Saarbrücken, 2017.

11. Cecílio, A. B.; Souza, R. J.; Braz, L. T.; Tavares, M.; Cienc. Rural 2000, $30,171$.

12. Baxter Jr., E.; Crime Scene Investigation, $1^{\text {st }}$ ed., CRC Press: New York, 2015.

13. Velho, J. A.; Geiser, G. C.; Espindula, A. Em Ciências Forenses: Uma introdução às principais áreas da criminalística moderna; Figini, A. R. L., ed.; Millenium: São Paulo, 2017, cap. 8.

14. Dam, A. V.; Van Weert, A.; Falkena, K.; Weymans, C.; Kloosterman, A.; Lambrechts, S. A. G.; Van Leeuwen, T. G.; Aalders, M. C. G.; Anal. Methods 2018, 10, 1413.

15. Daluz, H. M.; Fundamentals of Fingerprint Analysis, $1^{\text {st }}$ ed., CRC Press: New York, 2015.

16. Champod, C.; Lennard, C.; Margot, P.; Stoilovic, M.; Fingerprints and other ridge skin impressions, $2^{\text {nd }}$ ed., CRC Press: New York, 2016.

17. Hazarika, P.; Russell, D. A.; Angew. Chem., Int. Ed. 2012, 51, 3524.

18. Dam, A. V.; Beek, F. T. V.; Aalders, M. C. G.; Leeuwen, T. G. V.; Lambrechts, S. A. G.; Sci. Justice 2016, 56, 143.

19. http://www.quimica.net/emiliano/artigos/2006dez_forense1.pdf, acessada em agosto 2019.

20. Barros, H. L.; Stefani, H.; Forensic Sci. Int. 2016, 263, 83.

21. Sodhi, G. S.; Kaur, J.; Forensic Sci. Int. 2001, 120, 172.

22. Berneira, L. M.; Freitas, S. C.; Silva, C. C.; Machado, A. M.; Pereira, C. M. P.; Santos, M. A. Z.; Forensic Sci. Int. 2019, 296, 15.

23. Freitas, S. C.; Santos, M. A. Z.; Berneira, L. M.; Ortiz, R. S.; Pereira, C. M. P.; Sci. Justice 2019, 59, 190.

24. Conceição, L. D.; Pereira, C. M. P.; Forgie, A. H.; Leite, F. R. M.; Forensic Sci. Int. 2019, 297, 198.

25. Ribeiro, N. M.; Nunes, C. R.; Quim. Nova Esc. 2008, 29, 34.

26. Adams, R. P.; Identification of essential oil components by gas chromatography/mass spectroscopy, 2th ed., Allured Publishing Corporation: Carol Stream, 1995. 
27. Collins, C. H.; Braga, G. L.; Bonato, P. S.; Introdução a métodos cromatográficos, $7^{\text {th }}$ ed., Editora da Unicamp: Campinas, 1997.

28. Degani, A. L. G.; Cass, Q. B.; Vieira, P. C.; Quim. Nova Esc. 1998, 7 , 21.

29. Andrade, M. P.; Cardoso, M. G.; Batista, L. R.; Mallet, A. C. T.; Machado, S. M. F.; Rev. Cienc. Agron. 2012, 43, 399.

30. Solaiman, R.; Al-Zehouri, J.; J. Pharmacogn. Phytochem. 2017, 6, 726.

31. Singh, A.; Ahmad, A.; International Journal of Scientific \& Engineering Research 2015, 6, 318.
32. Moarefian, M.; Barzegar, M.; Sattari, M.; J. Food Biochem. 2013, 37, 62.

33. Naz, S.; Ilyas, S.; Parveen, Z.; Javed, S.; Asian J. Chem. 2010, 22, 3153.

34. Sears, V. G.; Bleay, S. M.; Bandey, H. L.; Bowman, V. J.; Sci. Justice 2012, 52, 145.

35. Cadd, S.; Islam, M.; Manson, P.; Bleay, S.; Sci. Justice 2015, 55, 219.

36. Chen, Q.; Kerk, W. T.; Soutar, A. M.; Zeng, X. T.; Appl. Clay Sci. 2009, $44,156$.

37. Friesen, J. B.; J. Chem. Educ. 2015, 92, 497. 